\title{
A Survey of Leisure Activities that the Elderly Desire
}

Sumalee Pumpinyo* and Saowaluck Koocharoenprasit

Faculty of Economics, Kasetsart University, Bangkok, Thailand

\section{ARTICLE INFO}

Keywords:

Activities

The Elderly

\begin{abstract}
The objective of this study was to explore both the indoor and outdoor activities that the elderly desire. This study employed a questionnaire and in -depth interviews with people aged 50 years and older in Bangkok, Prathum Thani, Samut Pragarn and Phra Nakhon Si Ayutthaya provinces .The sample size was 185 . The study showed that the outdoor activities that the elderly preferred were walking in the water, stretching activities and walking .The indoor activities that they preferred were muscle, brain and mind development .The most preferred outdoor activity of the elderly was walking in the water, while their favorite indoor activity was muscle development.
\end{abstract}

\section{Introduction}

Population ageing is already a challenge. Many countries in the world have ageing societies. In 1990, the share of people older than 60 years was around $9.2 \%$ and this increased to $11.7 \%$ in 2013. It is estimated that this number will grow to $21.1 \%$ in 2050 , for example, in China, Taiwan, Japan, German, and Hong Kong. Another estimate is that the world's elderly will increase by $60 \%$ in fifteen years. In 2030, total number of elderly people in the world will be around 1,000 million persons. It will increase to 1,600 million persons in 2050, as shown in Table 1 (United Nations, 2015).

Table 1.

Total number of adults older than 65 years in 2016, 2030 and 2050

\begin{tabular}{|c|c|c|c|c|c|c|c|c|c|}
\hline \multirow{2}{*}{ Year } & \multicolumn{3}{|c|}{ Total Population (persons) } & \multicolumn{3}{|c|}{ Population over 65 years (persons) } & \multicolumn{3}{|c|}{ Population over 65 years $(\%)$} \\
\hline & total & male & female & Total & male & female & total & male & female \\
\hline 2016 & $7,253.3$ & $3,652.0$ & 3,601 & 617.1 & 274.9 & 342.2 & 8.5 & 7.5 & 9.5 \\
\hline 2030 & $8,315.8$ & $4,176.7$ & $4,139.1$ & 998.7 & 445.2 & 553.4 & 12.0 & 10.7 & 13.4 \\
\hline 2050 & $9,376.4$ & $4,681.7$ & $4,694.7$ & $1,565.8$ & 698.5 & 867.3 & 16.7 & 14.6 & 18.5 \\
\hline
\end{tabular}

Source: U.S. Census Bureau, 2013; International Database

Thailand and Singapore will be the first group in Southeast Asia (SEA) in which the elderly will increase from $10 \%$ to $20 \%$. Other countries will also increase at a rapid rate (Table 2).

Table 2.

Years in which the proportion of the elderly will increase from $10 \%$ to $20 \%$ in SEA

\begin{tabular}{llllll}
\hline Country & Years & Number of years & Country & Years & Number of years \\
\hline Cambodia & $(2022-2047)$ & 25 & Malaysia & $(2018-2044)$ & 26 \\
\hline Brunei & $(2017-2030)$ & 13 & Philippines & $(2033-2073)$ & 40 \\
\hline Laos & $(2036-2057)$ & 21 & Singapore & $(1997-2019)$ & 22 \\
\hline Indonesia & $(2019-2045)$ & 26 & Thailand & $(2007-2021)$ & 14 \\
\hline Myanmar & $(2018-2587)$ & 26 & Vietnam & $(2013-2033)$ & 20 \\
\hline
\end{tabular}

Source: Population Division of the Department of Economic and Social Affairs of the United Nations Secretariat, World Population Prospects: The 2019 Revision (http://esa.un.org/unpd/wpp/index.htm)

* Corresponding Author E-Mail Address: fecosup@gmail.com 
Leisure activities (LA) can be defined as activities in which people engage during their free time. Engagement in leisure activities has been found highly beneficial to the elderly (Pressman et al., 2009, cited in Sala et al., 2019). Such activities help older adults to preserve their cognitive and physical function, as well as mental health. They thus contribute to successful ageing (Sala et al., 2019). Activities engagement is related to mental health as well. Mental health aspects such as wellbeing and life satisfaction have been found to positively correlate with LA engagement in several studies (Paggi et al., 2016, cited in Sala et al., 2019). The health benefits of such activities are also well documented and include lowered risk of disability (James, Boyle, Buchman, \& Bennett, 2011 cited in Holtfreter et al., 2017). An understanding of how older adults conceptualize healthy ageing and meeting the needs of the elderly are important for the development of policies, programs, and services designed to promote health. This may help with development of health-related policies, programs, and services that promote healthy ageing, and consequently, reduce health care system costs. The current study aimed to examine the leisure activities that the elderly desire which can support sustainability in the health of older persons in their successful ageing.

\section{Literature Review}

In a super-aged society, older people with reduced physical and sensory functions make up the majority of the population. Efforts must be made to prepare the urban environment, housing, and household equipment and appliances so that these people can live safely and comfortably. Collings (2001) revealed the perspective of successful old age was not one necessarily characterized by good health, but rather by an individual's ability to successfully cope with declining health.

The study of Kwok Yan Chi Jackie (2013) projected the living environment for an ageing society. In the case of Hong Kong, he studied daily life and the quality of life in Hong Kong by interviewing 50 older persons aged between $60-79$ years. The study showed that when the elderly has good financial means, ageing is not an obstacle, while the poorer have more difficulty and often fall into depression. Gunnarsson (2009) did small focus group interviews of healthy older persons. The results show economic growth and good welfare affect the health of the elderly. Depression in later life is also associated with reduced social and leisure activities (Victor, Scambler, Bond, \& Bowling, 2000; Zhang \& Li, 2011 cited in Holtfreter et al., 2017). Some of the more dire consequences of depression in late adulthood, such inactivity, adversely affect one's overall wellbeing and successful ageing. Over the past several decades, researchers have consistently demonstrated that reduced social activity results in a wide array of negative consequences, including increased isolation and reduced health Holtfreter et al., 2017. Researchers have also shown that sustained social and leisure activities can promote overall wellbeing and successful ageing (Moos et al., 2006). As noted above, one potentially harmful outcome stemming from depression is decreased participation in social and leisure activities. There is also evidence for a reverse causal chain in that lack of social activity may be a precursor to depression. Successful ageing is best characterized by the concurrent presence of three dimensions, namely high cognitive and physical function, low probability of disease and disability, and active engagement in life Rowe and Kahn (1987) cited in Sala, 2019. The study of Sala et al. (2019) shows that active engagement in leisure activities can help older adults to maintain cognitive, physical, and mental health.

\section{Research Methodology}

This study collected survey data from interviews conducted among healthy people in three age groups, 50-60 years, 61-70 years, and 71 years and older. Interviews were done in a public park as well as in public and private homes for the elderly in Bangkok, Prathum Thani, Samut Pragarn and Phra Nakhon Si Ayutthaya. The interviews were conducted from March to May 
of 2018. Data collected comprised purposive sampling among the aged. There were 185 samples, interviewing 50-60 year olds (144 samples), 61-70 year olds (28 samples) and people 71 years and older (13 samples). Questionnaire responses used a three-point Likert scale implemented to assess the respondents' opinions of leisure activities. Then, a weighted average index (WAI) (Black and Champion, 1976) was applied to develop the results. WAI values of $0.00-0.33$ indicate less interest, while $0.34-0.66$ show more interest, and $0.67-1.00$ indicate the most interest. These elders were sorted by their desired activities on the basis gender and age.

\section{Results}

From basic data, most people sampled were females aged between 50-60 years that are married with two children. Among this group, 46\% completed a bachelor's degree, while $41 \%$ held master's degrees. Most of them were employed by private companies with salaries of more than 50,000 baht per month (Table 3).

Table 3.

Basic data $(n=185)$

\begin{tabular}{|c|c|c|}
\hline Data & Number & Percent \\
\hline \multicolumn{3}{|l|}{ 1. Gender } \\
\hline Male & 57 & 31 \\
\hline Female & 128 & 69 \\
\hline \multicolumn{3}{|l|}{ 2. Age (years) } \\
\hline $50-60$ & 144 & 78 \\
\hline $61-70$ & 28 & 15 \\
\hline $71-80$ & 11 & 6 \\
\hline More than 81 & 2 & 1 \\
\hline \multicolumn{3}{|l|}{ 3. Education } \\
\hline Senior secondary & 20 & 11 \\
\hline Bachelor's degree & 86 & 46 \\
\hline Master's degree & 75 & 41 \\
\hline Doctoral degree & 4 & 2 \\
\hline \multicolumn{3}{|l|}{ 4. Status } \\
\hline Single & 58 & 31 \\
\hline Married & 103 & 56 \\
\hline Widowed/Divorced & 24 & 13 \\
\hline \multicolumn{3}{|l|}{ 5. Occupation (age 50-60 years) } \\
\hline State enterprise employee & 19 & 14 \\
\hline Private company employee & 53 & 37 \\
\hline Personal business/self-employed & 41 & 28 \\
\hline Civil service & 28 & 19 \\
\hline Maid & 3 & 2 \\
\hline \multicolumn{3}{|l|}{ 6. Former Occupation (over 61 years) } \\
\hline State enterprise employee & 4 & 10 \\
\hline Private company employee & 13 & 32 \\
\hline Personal business/self-employed & 5 & 12 \\
\hline Civil service & 16 & 39 \\
\hline Maid & 3 & 7 \\
\hline \multicolumn{3}{|c|}{ 7. Income of age $50-60$ years (baht per month) } \\
\hline Less than 10,000 baht & 3 & 2 \\
\hline $10,000-20,000$ & 7 & 5 \\
\hline $20,000-30,000$ & 14 & 10 \\
\hline $30,000-40,000$ & 27 & 19 \\
\hline $40,000-50,000$ & 14 & 10 \\
\hline Over 50,000 & 79 & 54 \\
\hline \multicolumn{3}{|c|}{ 8. Income (age over 60 years in baht per month) } \\
\hline Less than 10,000 baht & 10 & 24 \\
\hline $10,000-20,000$ & 11 & 27 \\
\hline
\end{tabular}




\begin{tabular}{lcc}
\hline Data & Number & Percent \\
\hline $20,000-30,000$ & 1 & 2 \\
$30,000-40,000$ & 3 & 8 \\
$40,000-50,000$ & 5 & 12 \\
Over 50,000 & 11 & 27 \\
9. Number of Children & & \\
0 & 74 & 40 \\
1 & 34 & 18 \\
2 & 58 & 31 \\
3 & 18 & 10 \\
More than 3 & 1 & 1 \\
\hline
\end{tabular}

The three most desired indoor and outdoor leisure activities were, in descending order, swimming, muscle development activities and stretching activities. The most popular outdoor activities were swimming, stretching activities and sports. The indoor activities that they desired were muscle, brain and mental development activities, as shown in Table 4.

Table 4.

Ranking of indoor and outdoor leisure activities that the elderly desire

\begin{tabular}{lc}
\hline Desired leisure activities & WAI \\
\hline Outdoor leisure activities & 0.6526 \\
Sports & 0.6224 \\
Gardening & 0.4685 \\
Offsite travel & 0.4919 \\
Bicycle riding & 0.6602 \\
Stretching activities such as Yoga, Tai Chi, Dance & 0.6785 \\
Swimming & 0.5957 \\
\hline Total & \\
\hline Indoor leisure activities & 0.6215 \\
Mental development activities such as singing, music lessons & 0.6731 \\
Muscle development activities such as drawing, fitness, dance & 0.6340 \\
Activities for brain development such as chess, playing cards, playing games & 0.5625 \\
Other activities such as cooking classes & 0.6054 \\
Relaxing massages, spa treatments & 0.4359 \\
Lectures for mental stimulation & 0.5423 \\
Participate in discussions and exchange opinions & 0.5821 \\
\hline Total & \\
\hline WAI = 0.00 - 0.33 = less interest, $0.34-0.66=$ more interest, $0.67-1.00=$ most interest
\end{tabular}

The study found that males and females were interested in the same indoor and outdoor activities, but overall, females had a greater rate of participation than males. Outdoor activities like swimming or walking in water and stretching activities were popular, while indoor activities such as muscle development, mental development, relaxing massages and spa treatments were sought after. Males were not interested in lectures for mental stimulation and cooking classes, while females did not prefer these lectures or participation in discussions and exchange of opinions (Table 5). 
Table 5.

Ranking desired leisure activities on the basis of gender

\begin{tabular}{|c|c|c|}
\hline \multirow{3}{*}{ Desired Leisure Activities } & \multicolumn{2}{|c|}{ Gender } \\
\hline & Male $(n=57)$ & Female $(n=128)$ \\
\hline & WAI & WAI \\
\hline \multicolumn{3}{|l|}{ Outdoor leisure activities } \\
\hline Sports & 0.6422 & 0.6599 \\
\hline Gardening & 0.6264 & 0.6210 \\
\hline Offsite travel service & 0.4583 & 0.4722 \\
\hline Bicycle riding & 0.4762 & 0.5000 \\
\hline Stretching activities such as Yoga, Tai Chi, Dance & 0.6618 & 0.6596 \\
\hline Swimming & 0.6759 & 0.6799 \\
\hline Total & 0.5901 & 0.5988 \\
\hline \multicolumn{3}{|l|}{ Indoor leisure activities } \\
\hline Mental Development activities such as singing, music lessons & 0.6081 & 0.6276 \\
\hline Muscle development activities such as drawing, fitness, dance & 0.6742 & 0.6725 \\
\hline $\begin{array}{l}\text { Activities for brain development such as chess, playing cards, } \\
\text { playing games }\end{array}$ & 0.6856 & 0.5948 \\
\hline Other activities such as cooking classes & 0.3958 & 0.5958 \\
\hline Relaxing massages, spa treatments & 0.5256 & 0.6242 \\
\hline Lectures for mental stimulation & 0.3810 & 0.4561 \\
\hline Participate in discussions and exchange opinions & 0.5278 & 0.5481 \\
\hline Total & 0.5426 & 0.5885 \\
\hline
\end{tabular}

$\mathrm{WAI}=0.00-0.33=$ less, $0.34-0.66=$ more interest, $0.67-1.00=$ most interest

The elderly generally liked the same indoor and outdoor activities regardless of their age. The current study found that they became more interest in walking in water as their age increased. Activities in which they had low interest as their age increased were participation in discussions and exchanging opinions as well as relaxing massages and spa treatments (Table 6).

Table 6.

Ranking desired leisure activities on the basis of age

\begin{tabular}{|c|c|c|c|}
\hline \multirow{3}{*}{ Desired leisure activities } & \multicolumn{3}{|c|}{ Age (year) } \\
\hline & $50-60(n=144)$ & $61-70(n=28)$ & over $70(n=13)$ \\
\hline & WAI & WAI & WAI \\
\hline \multicolumn{4}{|l|}{ Outdoor leisure activities } \\
\hline Sports & 0.6494 & 0.6667 & 0.6458 \\
\hline Gardening & 0.6431 & 0.4630 & 0.5000 \\
\hline Offsite travel & 0.4823 & 0.3810 & 0.5000 \\
\hline Bicycle riding & 0.4810 & 0.5556 & 0.5556 \\
\hline Stretching activities such as Yoga, Tai Chi, Dance & 0.6618 & 0.6917 & 0.5278 \\
\hline Swimming & 0.6455 & 0.7143 & 0.9048 \\
\hline Total & 0.5939 & 0.5787 & 0.6057 \\
\hline \multicolumn{4}{|l|}{ Indoor leisure activities } \\
\hline Mental development activities such as singing, music lessons & 0.6178 & 0.6491 & 0.5952 \\
\hline Muscle development activities such as drawing, fitness, dance & 0.6386 & 0.7727 & 0.8571 \\
\hline Activities for brain development such as chess, playing cards, playing games & 0.6447 & 0.5833 & 0.6458 \\
\hline Other activities such as cooking classes & 0.5650 & 0.5000 & 0.6111 \\
\hline Relaxing massages, spa treatments & 0.6415 & 0.4815 & 0.4722 \\
\hline Lecturers for stimulation & 0.4352 & 0.3333 & 0.5417 \\
\hline Participate in discussions and exchange opinions & 0.5621 & 0.4792 & 0.4167 \\
\hline Total & 0.5864 & 0.5427 & 0.5914 \\
\hline
\end{tabular}

WAI of $0.00-0.33=$ less interest, $0.34-0.66=$ more interest, $0.67-1.00=$ most interest 


\section{Discussion and Recommendations}

From the study, swimming, stretching and muscle development activities are the best activities for healthy ageing. Activities for the elderly are very important to enable them to successfully cope with declining health (Collings, 2001). Lack of activity will increase isolation and reduce health. Furthermore, lack of social activity may be a precursor to depression (Moos, et al., 2006). Leisure activities can help older adults to maintain their cognitive, physical, and mental health (Sala et al., 2019). The government should develop policies supporting activities for the elderly. Gunnarsson (2009) points out that good welfare is arises from many activities for the elderly, promoting their good health. Home care both, private and public, should be concerned with and provide indoor and outdoor activities such as swimming, drawing, yoga, and game playing, among others. This is to develop both physical and mental health in the advanced years of our elderly citizens.

\section{References}

Black, A. and Champion, Dean J. (1976). Methods and Issues in Social Research. John Wiley \& Sons, Inc.

Collings, P. 2001. "If you got everything, it's good enough": Perspectives on successful aging in a Canadian Inuit community. Journal of Cross-Cultural Gerontology, 16, 127-155.

Gunnarsson, E. 2009. 'I Think I have had a Good Life '; The Everyday Lives of Older Women and Men from a Life Course Perspective Ageing and Society,

Holtfreter K., Reisiga, M., Turanovicb. J. 2017. Aging \& Mental Health, Depression and infrequent participation in social activities among older adults: the moderating role of high quality familial ties Vol. 21, No. 4, 379-388,

Kwok Yan Chi Jackie. 2013. Projecting Sustainable Living Environment for an Ageing Society: The case of Hong Kong. Procedia Environmental Sciences 17, P. 675-684.

Moos, R.H., Brennan, P.L., Schutte, K.K., Moos, B.S. (2006). Older adults' coping with negative life events: Common processes of managing health, interpersonal, and financial/work stressors. International Journal of Aging \& Human Development, 62, 39-59.

Sala G., Jopp D., Gobet F., Ogawa M., Ishioka Y., Masui Y., et al. 2019. The impact of leisure activities on older adults' cognitive function, physical function, and mental health. PLoS ONE 14 (11): e0225006.

United Nations. 2015. Department of Economic and Social Affairs, Population Division. World Population Prospects: The 2015 Revision.

U.S. Census Bureau. 2013. International Database. 